\title{
Shifting Labor Structure in Line with the Requirements of Industrial Revolution 4.0 in Vietnam
}

\author{
Ph.D - Main lecturer: Nghia, Nguyen Trong \\ Rector, University of Finance - Business Administration
}

\begin{abstract}
Vietnam is in the process of international economic integration, along with the strong development of science and technology in the era of industrial revolution 4.0. Industrial revolution 4.0 will create major changes in labor supply and demand, the labor market will be seriously challenged between labor supply and demand as well as labor structure. In order to take advantage of the opportunity and catch up with the 4.0 Revolution, Vietnam needs to improve the level of skilled workers and use high technology, the ability to quickly adapt to changes in new production technology. Modern, effective use of modern technology application, suitable to our country's conditions.
\end{abstract}

Keywords: Labor structure, labor restructuring, industrial revolution 4.0, Vietnam DOI: $10.7176 / \mathrm{JESD} / 10-2-15$

According to the International Labor Organization (ILO), Vietnam is one of the countries most affected by the industrial revolution 4.0. Unskilled occupations at simple levels of training will be highly impacted and at risk of unemployment due to the development of automated technology and artificial intelligence. In particular, the background. In some areas, with the emergence of robots, the number of employees needed will be only $1 / 10$ of the current level. Thus, the remaining $9 / 10$ will have to change jobs or be unemployed. And during the 4.0 industrial revolution, many industries will disappear but new jobs are born. Before the trend of automated machines to replace people, human resources must equip appropriate knowledge and skills to meet the work requirements in the new situation.

\section{Requirements of industrial revolution 4.0 for Vietnam's labor restructuring.}

Industrial revolution 4.0 is based on 3 main areas: Digital, biotechnology; New generation robots, self-driving cars, new materials ... According to experts' estimates, the Industrial Revolution 4.0 will be the foundation for a strong economic transformation from a resource-based, labor-based model. low-cost dynamic to knowledge economy; fundamentally altering the concept of technology and equipment innovation in production lines.

"Labor structure is the relation of labor ratio divided according to some economic criteria" ${ }^{1}$

"Labor restructuring is the process of changing and objectively transforming from the old labor structure to the new and improved labor structure, more suitable to the process and level of socio-economic development" 2 .

In Vietnam, the adjustment of labor structure takes place on the basis of economic transition towards industrialization and modernization, international economic integration, aiming at economic growth and development. Assembly, improve labor productivity, create jobs and improve people's lives. In order to meet the current requirements of the industrial revolution 4.0, Vietnam's labor restructuring is revolutionary in the redivision of labor with the aim of increasing the rate of technical and skilled workers. high labor in modern industries and service The quality of labor in our country is low, not meeting the requirements of economic development, the structure of training occupations has many shortcomings. There is a serious shortage of highly qualified technical workers, labor in some new industries. The rate of trained workers is low, skills, skills, physical strength and industrial working style are still weak, so the competitiveness of Vietnamese workers is low. There is still an imbalance between supply and demand for local labor between regions, regions and economic sectors. While labor supply is large, there are still many businesses facing difficulties in recruiting workers, not only trained workers but also difficult in recruiting unskilled workers. The quality of employment is low, self-employed workers, unpaid family workers and workers working in informal production and business establishments are still the three main groups of workers in the economy. Many wage employees only have verbal contracts or even no contracts. And unemployment increased sharply in people with high qualifications (from university and above).

Slow labor restructuring, Labor mainly works in the agricultural sector, the informal sector, low productivity. The economy still relies heavily on resource exploitation and labor-intensive industries (agricultural, aquatic and mining products, primary industrial products and consumer services using a lot of unskilled workers). ).

\footnotetext{
${ }^{1}$ Topic "theoretical and practical bases to continue to renovate policies and solutions to shifting rural labor structure, Institute of Labor and Social Sciences

${ }^{2}$ Study the factors affecting the movement of rural labor in Vietnam - Institute of Scientific and Social Labor
} 
Currently, the Ministry has units to carry out researches, forecasts about employment and labor market, in which research and information on issues such as: size and quality of the workforce are studied; employment trends; informal employment; labor shift in the market; unemployment; labor productivity; labor market in coastal areas; subjects and trends of participation in unemployment insurance; youth employment; the impact of international integration on the labor market ... specifically through many products such as: Vietnam employment trend report (published annually); Report assessing the position displacement of workers on the post-WTO labor market; Report Analyzing the situation of labor use and forecasting labor demand in Vietnamese enterprises; Vietnam Labor Market Research Report in the context of strengthening ASEAN regional cooperation on economy and labor: Opportunities and challenges; Analysis report, assess the impact of the Industrial Revolution 4.0 on the Vietnamese labor markets.

According to the World Labor Organization (ILO) forecast, Vietnam will be able to create 6 million more jobs, equivalent to one tenth of the total number of jobs increased by 2025 of the entire ASEAN region due to the impact. from the formation of the AEC. When joining the AEC, the number of jobs in Vietnam will increase by $14.5 \%$ by 2025 . In the period of 2016 - 2025, the demand for recruiting personnel will form 03 levels of human resources: high-level technical expertise (up $41 \%$ - 14 million places of work), middle technical expertise (up 22\% - 38 million jobs), low-level technical expertise (up 24\% - 12.4 million jobs). According to the agreement in the framework of the ASEAN Economic Community (AEC), there are 08 occupations in which skilled skilled workers are allowed to move within 10 ASEAN countries to recognize the equivalent value of training certificates. Member countries are technical services, nursing services, architecture, construction supervision, accounting, doctors, dentists, travel. According to documents published by the International Labor Organization (ILO) and according to research data of economic experts from seminars published in 2017 - 2018 , shows: In the Industrial Revolution 4.0, The prospect of smart factories - in which machines are connected to the Internet and linked together through a system, can envision the entire production process and make decisions looks no longer far away half.

According to the analysis "the fourth industrial revolution" leads to job losses due to the boom in artificial intelligence, nanotechnology, 3D printing, genetics and biotechnology. They lead to confusion not only in the business environment but also in the labor market because new skills are required to meet new conditions.

In addition, increasing labor demand is data analysis, professional sales and new types of human resources as well as materials, biochemistry, nanotechnology and robot related experts. Other areas of expected unemployment are health care, energy, financial services, production investment, especially low-skilled workers. In order to take advantage of the opportunities and catch up with the Industrial Revolution 4.0, Vietnam needs to start from the simplest, most essential and sustainable things, to develop high-tech human resources.

\section{Major challenges to Vietnam's labor restructuring in the industrial revolution 4.0}

With a population of over 94 million people today, of which the labor force aged 15 and over is 54.61 million people, accounting for $59.5 \%$, Vietnam is still in the golden population period with labor supply. Abundant and stable. Figure 1 shows that the population aged 15 and over in Vietnam is still increasing (from Q2 / 2012 to the second quarter of 2017, the population increased by 3.4 million), the labor force in this period still increased above 1, 9 million people) and the labor force participation rate remains stable.

Figure 1: Population aged 15 and over and Vietnam labor force Q2 / 2012, Q 2/2017

Unit of calculation: thousand people

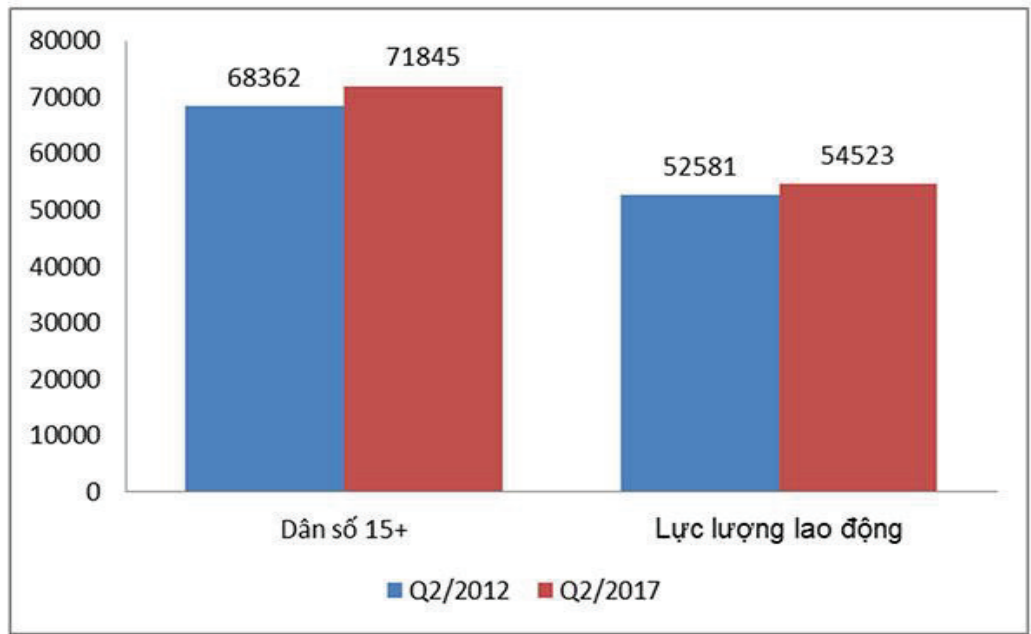

(Source: Labor force survey, GSO)

Regarding technical and professional qualifications: Chart 2 shows that the labor force with high 
technical and professional qualifications increased in the period of Q2 / 2012 to Q2 / 2017. The proportion of workers without technical qualifications decreased 5.10 percentage points, the rate of workers with elementary qualifications increased by 1.08 percentage points, the rate of workers with college degrees increased by 0.80 percentage points and the highest increase are the proportion of workers with university degrees increasing by 3.00 percentage points.

Figure 2: Technical qualification of the labor force Q2 / 2012 to quarter 2/2017

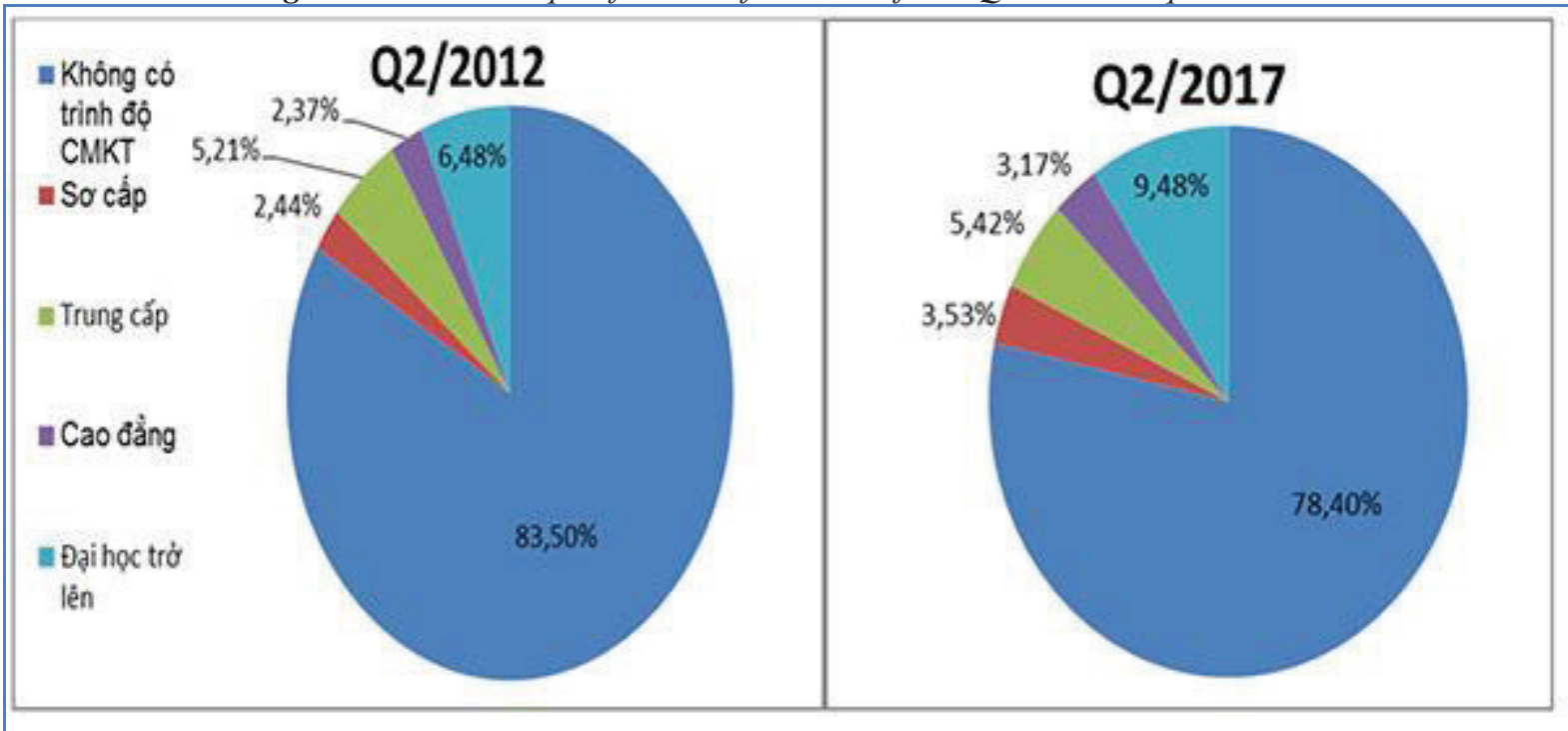

Source: Labor force survey

However, the quality of labor force in Vietnam is still very limited; in which the rate of trained workers is still low, the shortage of skilled workers has not met the demand of the labor market and integration; The gap between vocational education and the demand of the labor market is growing. When considering the problem of unemployment in terms of technical qualifications, the unemployment rate tends to increase among high-skilled workers. According to the Labor Market Newsletter No. 15, at the time of Quarter 3, 2017, the number of unemployed people with university and above qualifications increased by 53.9 thousand people compared to the second quarter of 2017 at 237 thousand people, equivalent to $4,51 \%$.

The trend of unemployment has increased for many reasons, but most importantly, the quality of training in universities and colleges is not high, so new graduates do not meet the recruitment needs of business agencies. career. At the same time, the shift of model, economic structure makes the supply and demand of labor change, while the training sectors in the school have not caught up with the trend of labor use of enterprises. Besides, the labor market information system does not reflect objectively and promptly the volatility of the labor market; The mid-term and short-term forecasts on the labor market have not yet been released and the low efficiency of employment services has contributed to this trend.

Firstly, labor migration will create a cooperative environment, healthy competition and fierce competition. The biggest challenge is that the competitiveness in the labor market will be very high, while the level of readiness of vocational education in Vietnam is still slow. Competition between our country and other countries in the world in providing high quality labor resources requires the quality of vocational education to be significantly improved in the direction of approaching regional standards and so Gender to enhance the ability to recognize diplomas between Vietnam and other countries.

Secondly, in the next year, Vietnam will face the problem of aging population which will make the young labor force lose gradually over time. Another problem is that the economy will be severely affected by climate change, causing some sectors to decline sharply and a competitive advantage.

Thirdly, the ability of students to graduate after graduation in a new working environment. To achieve this, there are two determinants that less educated students in the school are English and industrial style. Adaptability to change, practical skills and consciousness, working style are also significant challenges for Vietnamese workers.

Fourthly, competition for high quality human resources will take place strongly on the world, regional and national levels. The opening of the ability to move labor between countries requires workers to have high occupational skills, capable of working in an international environment with standards and criteria determined by the labor market. . According to experts from the World Bank (WB), the preparation of knowledge and skills; The attitude and psychology to be ready to move to work in ASEAN countries of Vietnamese workers is not high.

Fifthly, Vietnam's labor productivity is still low. The unevenness of the quality of human resources in the 
country and in the region in the context of high requirements on vocational skills and rapid innovation in products and services. Science and technology have not really become a driving force to improve labor productivity, competitiveness, and promote socio-economic development. There is no strong enough solution to encourage businesses and attract private investment for research, innovation and application of science and technology.

Sixthly, the quality of jobs is low, while the ability to create jobs of the economy in the period of decline, economic growth is not high, affecting the results of job creation for workers. Resources to support job creation are low, not guaranteed to implement programs and projects to support job creation. Labor restructuring is still slow, laborers working in the agricultural sector still account for a high proportion; labor quality is low, the proportion of trained workers is $51.6 \%$, of which 3 months or more of training (with certificate) is only about $21.9 \%$.

Seventhly, the labor market in the country and in the world requires employees to achieve professional standards, but the system of national occupational skill standards is being built and initially towards regional and world standards. Managing foreign workers into Vietnam to work is still loose; access to information on overseas labor market is still limited. Operating information system of labor market in Vietnam is still inadequate. The reality of the labor market is paradoxically abundance of labor but lacks of highly qualified human resources for occupations in the development orientation. In the process of integration, enterprises tend to recruit not too much of a degree. Advanced degree is not a decisive factor in easy or difficult job application, human resources are suitable for recruitment requirements, ensuring professional knowledge and vocational skills are the main factors that bring workers to the city. public. The professional and skilled labor force is currently very lacking, enterprises want to recruit without. However, most students - graduates do not immediately meet the requirements of work, practical skills and weak and lack of soft skills knowledge, the gap between learning theory and practical work big.

Background in 2018, can open a view of the present and the coming years. Advanced degree is not a decisive factor in easy or difficult job application, human resources are suitable for recruitment requirements, ensuring professional knowledge and vocational skills are the main factors that bring workers to the city. public.

\section{Solution of labor restructuring to meet the industrial revolution 4.0 in Vietnam}

Promote the implementation of the national strategy on human resource development. Basic and comprehensive innovation and improving the quality of education and training, especially vocational training, training of high quality human resources to meet the needs of the quantity and quality of human resources for economic development private. Strengthening cooperation and close links between businesses and training institutions; planning and development of training according to the needs of businesses and markets (Resolution of the fourth conference on private economic development)

Firstly, the youth orientation is to choose suitable jobs, promote the process of freedom of employment and labor transfer

Meeting the demand of economic restructuring towards industrialization and international economic integration. Constructing synchronous labor market infrastructure (career guidance, employment services, labor market information and forecasts) and effective public service delivery organizations.

Industrial revolution 4.0 increases the risk of job loss, unemployment, and many industries face major challenges due to fierce competition. There have been warnings that Vietnam will lose 5 million jobs by 2020 because the quality of human resources is only 3.79 points (10 point scale); ranking 11 th in 12 countries in Asia participating in the ranking and the number of human competition 4.3 / 10 points. In addition, other indicators are also very low such as competitiveness of $4.3 / 10$, ranking 56/133 countries; the rate of trained workers with certificates / certificates in 2015 was only $20.3 \%$. Vietnamese human resources still lack soft skills such as foreign languages, information technology, teamwork skills, communication, industrial behavior and responsibility, professional ethics.

Secondly, overcome the low quality of labor, build healthy labor relations and improve the capacity of entities in the labor market, especially the management, organization, regulation and support the development labor market of the State.

The quality of labor in our country is still very low, not meeting the requirements of economic development, the structure of vocational training has many shortcomings, lack of high-level labor, vocational education system, vocational training. not yet meeting the labor market demand ... This is the reason why Vietnam's labor productivity is low, far behind many countries in the world and in the region. In particular, before the fact that unskilled workers are gradually replaced by machinery and require higher labor skills, before the 4.0 industrial revolution, solutions should be given to overcome these problems. limitations and challenges in the coming time.

Globalization and integration are a major development trend in international relations in all aspects, especially in the economic sector, through commitments and agreements. Vietnam has become members of the ASEAN Economic Community (AEC), Free Trade Agreement (FTA) between the EU and Vietnam, 
participating in CPTPP, international institutions will promote the flow of Because of goods, services, investment, technology and labor, especially skilled workers have the opportunity to move in the labor market of the AEC. Mutual recognition agreements (MRAs) between ASEAN countries on professional standards, qualifications and skills ... are important tools for the freedom to move skilled and skilled workers. Rising exports are seen as an important factor to create jobs. Besides, direct investment from abroad into Vietnam will also contribute to changing the economic face and creating millions of jobs.

Opportunities to develop vocational education: creating many opportunities in mutual cooperation between vocational education institutions; opportunities for learning, retraining, exchanging and improving qualifications for teachers and professional education managers; There will be more foreign investment resources in the field of vocational education, etc. Supporting disadvantaged groups in the labor market, enhancing social security for workers while working and changing jobs. do. Enhance the participation of workers in the social insurance regime. Strengthen the ability to prevent and overcome risks of employment and income of workers.

Thirdly, it is necessary to improve the quality of analyzing and forecasting the labor market, connecting with enterprises in vocational training

Analysis of the labor market forecast is the basis for improving the quality of human resource training, because if not well the forecast of supply and demand will only train the contents of the schools, not the labor market. Dynamic need. Need to do well the forecast of labor supply and demand in the vocational education sector, implement synchronously solutions to improve the quality of vocational education; develop a project to support young people and start-up students. Participate in building training programs and curricula; organizing teaching, guiding practice and assessing learning results of learners at vocational education establishments; organize training and retraining to improve occupational skills and re-train jobs for laborers of enterprises; Expenses for professional training activities of enterprises shall be deducted when determining taxable incomes according to the provisions of tax law; Provide information on training needs, labor use of enterprises according to industry, occupation and demand for annual recruitment of state management agencies for vocational education. Promote the implementation of the mechanism of negotiation and agreement on wages to ensure real wages are paid in accordance with the market mechanism and in accordance with the contribution of workers to the growth process.

Fourthly, develop a training scheme for workers without qualifications

The full statistics on the level of training, the rate of trained workers with jobs, the rate of unemployed in our country today has not been well done. Statistics on university, college, and intermediate degrees have been relatively good, but other training statistics do not have a good certificate. Statistics of Vietnam data are slightly different from other countries in the world. Vietnam's statistics are mainly statistics on qualifications, not labor statistics. The labor structure according to Vietnam's level is "middle shape"; but the labor structure of the Vietnamese market is in line with the model of developing countries - "pyramid". In less developed countries, pyramids are very high; in developing countries lower pyramids, similar to "equilateral triangles"; In developed countries, the model is like "potato" or "egg". In Vietnam, the labor model is a pyramid and there are signs of gradual transition to "egg" or "potato".

Fifth, expanding the labor market and international integration

Vietnam is in a period of international integration through the formation of the ASEAN Community and new generation free trade agreements. Acquiring relevant career and skills knowledge, which means Vietnam will respond well and benefit from development and will be an attractive place for businesses from all over the world to invest. The continuous renovation of education and vocational training is an important goal of the National Socio-Economic Development Strategy, the need to improve the quality of the workforce will be key to further modernizing the economy. and sustainable development in Vietnam.

With the opportunities for economic development opened from the deeper integration into the economy, when signing many free trade agreements and joining the ASEAN Economic Community (AEC), the human resource needs of Vietnam is expected to increase sharply.

Thus, the Technology Revolution 4.0 is made and decided by people.

Even how smart a robot is, equipped with artificial intelligence, the human being is the core, irreplaceable. Therefore, workers are forced to equip themselves with new knowledge and skills, meeting the requirements of technology application 4.0, especially specialized in information technology.

\section{Conclude}

The Vietnamese labor market still has certain limitations. That is, workers mainly work in agricultural areas, non-structural areas, low productivity, basically Vietnam is still an excess labor market in agriculture and rural areas with the quality of labor supply. low dynamic, unreasonable allocation and limited mobility; labor demand is low in quantity and there is still a large proportion of workers working in simple occupations, which do not require technical expertise, slow-growing wage employment areas; The underemployment rate is still quite high; the legal system of the labor market is incomplete; the uneven development of the labor market infrastructure 
leads to the inability to connect labor supply and demand; there is an imbalance in local labor supply and demand, although a lack of employment accounts for a large proportion, but some industries, localities .. cannot recruit workers; education, vocational and training systems have not met the demand of the labor market, especially for workers with high skill requirements; a large number of unprotected workers in the market.

\section{References}

1. General Statistics Office, Report on socio-economic situation in the period of 2001-2016;

2. General Department of Customs (2016), Export turnover in the period of 2001-2016;

3. National Center for Socio-Economic Information and Forecasting (2016), Key developments in the trade balance in the period of 2011-2015;

4. Dinh Tuan Minh, Phan Huy Hoang, Nguyen The Hoang (2017), Challenges of Vietnamese exports, Saigon Economic Times.

5. Topic "theoretical and practical bases to continue to renovate policies and solutions to shifting rural labor structure, Institute of Labor and Social Sciences

6. TS. Nguyen Ngoc Son, Labor and employment shift in Vietnam in the period ..., Economic and forecast journal, No. 2 (March 2006 